\title{
Trends of maternal health service coverage in the Democratic Republic of the Congo: a pooled cross-sectional study of MICS 2010 to 2018
}

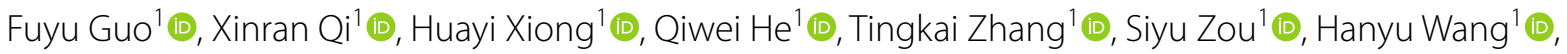
Rie Takesue ${ }^{2}$ and Kun Tang ${ }^{1^{*}}$ (D)

\begin{abstract}
Background: Maternal health services are essential for reducing maternal and newborn mortality. However, maternal health service status in the Democratic Republic of the Congo (DRC) remains poorly understood. This study aims to explore the trends of antenatal care (ANC) and skilled birth attendance coverage in the past decade in the DRC.

Methods: The 13,361 participants were from two rounds of Multiple Indicators Cluster Survey (MICS) conducted by the National Institute of Statistics of the Ministry of Planning of the DRC, in collaboration with the United Nations Children's Fund (UNICEF), in 2010 and 2017-2018. A regression-based method was adopted to calculate adjusted coverage of ANC and skilled birth attendance. Subgroup analysis based on different socioeconomic status (SES) was conducted to explore the impact of domestic conflicts.

Results: From 2010 to 2018, the overall weighted ANC coverage in the DRC declined from $87.3 \%$ (95\% Cl $86.1-$ $88.0 \%)$ to $82.4 \%$ (95\% Cl 81.1-84.0\%), while the overall weighted skilled birth attendance coverage increased from $74.2 \%$ (95 \% Cl 72.5-76.0\%) to 85.2\% (95\% Cl 84.1-86.0\%). Adjusted ANC coverage and adjusted skilled birth attendant coverage both declined in Kasai Oriental, but increased in Nord Kivu and Sud Kivu. In Kasai Occidental, ANC coverage declined, but skilled birth coverage increased. In the Kasai region, the largest decline in adjusted coverage of ANC was found among the poorest women. However, in the Kivu region, both the adjusted coverage of ANC and skilled birth attendance increased among the poorest women.

Conclusions: Due to ongoing conflicts, there has been a systemic deterioration of maternal healthcare coverage in some regions of the DRC, particularly among people with low SES. However, in other regions, maternal healthcare services were not severely disrupted possibly due to substantial international health assistance.
\end{abstract}

Keywords: Antenatal care, Skilled birth attendance, Violent conflicts, The Democratic Republic of the Congo

*Correspondence: tangk@mail.tsinghua.edu.cn

${ }^{1}$ Vanke School of Public Health, Tsinghua University, No. 30 Shuangqing

Road, 100084 Beijing, China

Full list of author information is available at the end of the article

\section{Background}

Timely and adequate maternal health services, including antenatal care (ANC), delivery care, and postnatal care (PNC), are critical to mothers and newborns [1]. Maternal health services including maternal health education, health checkups, immunization, and early identification and treatment of complications [2,3], have been widely 
advocated by many international health agencies [4]. However, in low-income regions (e.g., Western and Central Africa), maternal health service coverage is far from ideal. Approximately 99\% of global preventable maternal deaths occur in low-income countries, where women lack essential childbirth services $[5,6]$.

The maternal mortality ratio in the Democratic Republic of the Congo (DRC) is high, estimated at 473 maternal deaths per 100,000 live births in 2017 [7], far exceeding the global target of the Sustainable Development Goal 3.1 (SDG3.1), which aims to reduce the global maternal mortality ratio to less than 70 per 100,000 live births by 2030 [8]. The United Nations Children's Fund (UNICEF) reported that in 2018 , only $82.4 \%$ of women in the DRC have at least one antenatal care visit with skilled health care workers and only $80.1 \%$ have skilled attendance at delivery, both below the global average level [9-11]. Although maternal health services are widely promoted in Western and Central Africa, little is known about the status and trends of maternal health service coverage in the DRC.

Since its independence in 1960, the DRC has been plagued by civil unrest and political instability and is known as one of the poorest and the most fragile countries in the world $[12,13]$. There are continuing political instability and attacks in the Kivu regions, with a longlasting conflict 2004-2012, mainly focusing on illegal exploitation of mineral resources [14]. Even after 2012, although natural resources did not cause the wars in the DRC, there was a progressive "economization" whereby the violence became increasingly motivated by profit. On the contrary, the Kasai region was relatively calm until the violence broke out in 2016 between local militants and national government forces [15]. The area became the epicenter of an intercommunal conflict that spread to neighboring provinces. At its peak, up to 1.4 million internally displaced persons, has largely subsided [16]. The United Nations reported that 5000 people died in the violent conflict, which lasted over two years [17]. The violence, frequent mass displacement, and suspension of economic and farming activities have largely affected the physiological and safety needs of people, in particular women and children [18]. Consequently, the health system in the regions has deteriorated with the disruption of essential services $[19,20]$.

Since 1963, UNICEF has been providing support to the DRC, including health aid on maternal and child health, to assist with the impact of the conflicts [21]. Humanitarian assistance to the DRC previously focused on the Eastern DRC, especially the Kivu region, where the conflicts were concentrated in. The Kivu region has received significant maternal and child health aid for more than a decade [22]. On the contrary, such assistance to the Kasai region was insufficient [23, 24]. Although the United Nations declared a DRC Level 3 Emergency in October 2017 in the Kasai and surrounding regions in response to the Kasai conflict, aid was not given until April 2018 [25]. Given the regional differences in the DRC, it is important to understand the trends of maternal health service coverage at regional levels under different scenarios. The present study aims to investigate the trends in the coverage of ANC and skilled birth attendance during the past decade in the DRC, with subgroup analysis by socioeconomic statuses (SES). The findings of this study will provide a picture of the trends of maternal health service and serve as a reference for future policies and programs.

\section{Methods \\ Data Source}

Data from the 2010 and 2017-2018 Multiple Indicator Cluster Survey (MICS) in the DRC was utilized. The MICS has employed a set of survey tools to generate statistically sound and internationally comparable data in 116 countries and is one of the largest international household surveys programs developed by UNICEF. To date, there have been six rounds of the MICS, for which the DRC has taken part in MICS1 (1995), MICS2 (2001), MICS4 (2010), and MICS6 (2017-2018). Among the four rounds, MICS4 and MICS6 have similar questionnaire structures. Both MICS4 and MICS6 were conducted by the National Institute of Statistics with support from UNICEF. Following a standardized protocol, multi-stage stratified sampling processes were employed to obtain samples proportional to population size in each province. Due to a governmental decentralization process started in DRC in 2015, there was an increase in the number of provinces from 11 provinces to 26 provinces, which was accounted for in the 2018 MICS. A detailed outline of corresponding provincial boundaries can be found in Additional file Table S1 [see Additional file 1]. To generate valid estimates for each province, MICS6 in 2017-2018 sampled more families. Overall, the surveys included 11,393 (MICS4) and 20,792 (MICS6) households. Further details on sampling methods can be found in the MICS4 and MICS6 summary papers [11, 26].

\section{Participants}

Of 12,851 and 21,756 women aged 15-49 interviewed during the MICS4 and the MICS6 surveys, only participants who had live births within the two years preceding the surveys were included to assess the coverage of ANC and skilled birth attendance in their last delivery. For complete case analysis, two women in MICS6 with missing values were excluded. A total of 13,361 women, 4,807 (36.0\%) from MICS4 and 8,554 (64.0\%) from MICS6 were included in the final analyses. The flow diagram of 
the inclusion or exclusion of participants is presented in Fig. 1.

\section{Exposures}

The present study aims to explore the trends in coverage of ANC and skilled birth attendance among the provinces in the DRC. To make the province categories between MICS4 and MICS6 comparable, we recategorized the provinces in MICS6 into 11 old province categories in MICS4, including Katanga, Kasai Oriental, Kasai Occidental, Kinshasa, Bas Congo, Bandundu, Equateur, Province Orientale, Maniema, Nord Kivu, and Sud Kivu.

Additionally, we aimed to study the difference in trends of ANC coverage and skilled birth attendance among different wealth index groups. In the MICS datasets, the household wealth index was categorized into five quantiles (poorest, poorer, middle, wealthier, and wealthiest) based on an asset-based wealth index [27]. For the present study, household wealth index groups were used as proxies of participants' SES.

\section{Outcomes}

To ensure comparability with previous studies, we adopted the definitions from WHO [28]. Antenatal care coverage was defined as the percentage of women who utilized antenatal care provided by skilled health personnel for reasons related to pregnancy at least once during pregnancy among all women who gave birth to a live child in a given period. Qualified health personnel include physicians, nurses, and midwives. Skilled birth attendance coverage was defined as the proportion of births attended by skilled health personnel among all births. Information about whether the participants having at least one antenatal care provided by skilled birth attendants or having skilled attendance at delivery was retrieved from the MICS datasets. Data on whether antenatal care was received at least four times (ANC4) was also available. However, as the service providers of each visit were not clearly specified and there was a large number of missing data on visit times, the prevalence of ANC4 is presented in Additional file 2 as a description but is not included in the main analysis.

\section{Covariates}

Based on reviewed literature [29-33], we chose women's age, educational attainment, marital status, household heads' sex, and residence region as covariates. Women were classified into four age groups:15-19, 20-29, 30-39, and 40-49. Women's educational attainment was categorized into three groups: below the primary school, primary school, and secondary or higher school. Women's marital status information was also retrieved from the original datasets and re-categorized into two groups: currently single and married or living with a partner. For the residence region, it is worth noting that in MICS4 and MICS6, no participants were categorized as living in rural regions in Kinshasa.

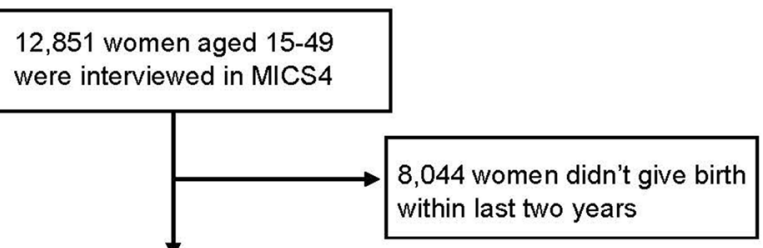

4,807 (37.4\%) women reported maternal health utilization in last pregnancy
21,756 women aged $15-49$

were interviewed in MICS6

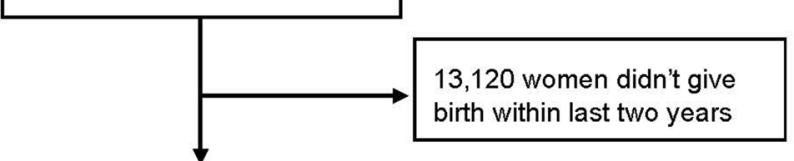

8,556 (39.3\%) women reported maternal health utilization in last pregnancy

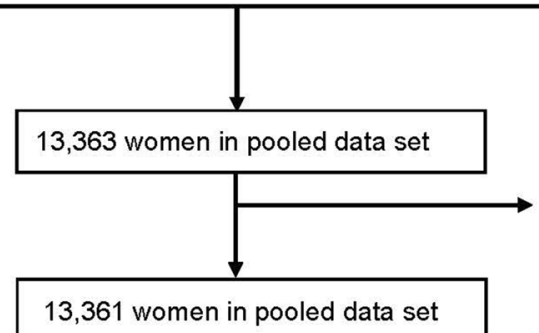

1 woman in MICS6 missed marital status information; 1 woman in MICS6 missed the provider of antenatal care information

Fig. 1 Flow diagram of the inclusionof participants 


\section{Statistical analysis}

Descriptive statistics were calculated to show the characteristics of survey participants. The overall coverage of ANC and skilled birth attendance was calculated using sampling weights provided in the MICS datasets. The weighted coverage was then compared with survey findings in the UNICEF reports $[11,26]$ to validate our analyses. A logistic regression-based adjusted prevalence method was used to calculate adjusted coverage of ANC and skilled birth attendance. Details for the method were described elsewhere [34, 35]. Briefly, the probability of the event (binary variable) for each individual was firstly modeled by constructing a logistic regression in which independent variables were the group variable such as province and the chosen adjusted variables (e.g., educational attainment, wealth index). Secondly, for each participant in the datasets, the probability as well as the standard error of the event was predicted using the model. Lastly, for each group, the mean of the probability of the event among the participants within the group was calculated. In this study, the coverage of ANC and skilled birth attendance for participants from different provinces in 2010 and 2018 were calculated, adjusted for women's age, educational attainment, marital status, household heads' sex, residence region, and household wealth status. Maps were drawn to visualize the trends in coverage of adjusted ANC and adjusted skilled birth attendance from 2010 to 2018 .

To further compare the trends between regions with conflict but who were largely unassisted (low humanitarian assistance, especially for maternal and child health, i.e., the Kasai region), regions with conflict but who were assisted (i.e., the Kivu region), and regions without such extensive conflict during 2010 and 2018 (other provinces), subgroup analyses were applied. In each region, adjusted ANC coverage and adjusted skilled birth attendance coverage with $95 \%$ confidence intervals in different wealth index groups were calculated. We chose the other provinces as a control group to reflect the influence of large conflict in the Kasai region and the Kivu region, as well as the influence of international health aid. Provinces around the Kasai region and the Kivu region might also be influenced by the conflict. To check if any province would significantly impact the results of the control group, we did a sensitivity analysis by dropping a province out of the control group in turns (Additional file 3). No significantly different trends between 2010 and 2018 were found in this analysis. Thus, to include as many as samples as possible as controls, we finally decided to aggregate the other provinces in a control group. Data were processed and analyzed using R 4.0.0 ( $\mathrm{R}$ Core Team, 2020).

\section{Results}

\section{Participants' demographic and socioeconomic} characteristics

A total of 13,133 women were included in the analyses, with 4,807 from MICS4 (2010) and 8,554 from MICS6 (2017-2018). Of all participants, roughly half were aged 20-29 years, with $54.8 \%$ participants in 2010 and $45.1 \%$ in 2018 . Only $37.5 \%$ of women had attended secondary school or higher. For women's marital status, about $87.0 \%$ of them were married or currently living with a partner, with no significant difference between 2010 and 2018. Most women came from the rural regions in the DRC, with $64.9 \%$ in 2010 and $73.5 \%$ in 2018. In 2010, the distribution of the SES of women was roughly even among five categories from the poorest to the wealthiest households. However, in 2018 more women were considered to live in the poorest and poorer households. Details for participants' demographic and socioeconomic characteristics are shown in Table 1.

\section{The trend of prevalence of maternal health care services from 2010 to 2018}

The overall weighted ANC coverage decreased from $87.3 \%$ (95\% CI $86.1-88.0 \%$ ) to $82.4 \%$ (95\% CI $81.1-$ $84.0 \%$ ) in 2018, and the weighted skilled birth attendance coverage increased from $74.2 \%$ (95\% CI 72.5-76.0\%) to $85.2 \%$ (95\% CI 84.1-86.0\%) in 2018 [Table 1].

As shown in Fig. $2(A)$, the adjusted ANC coverage declined in most provinces in the DRC, except in Kinshasa, Nord Kivu, and Sud Kivu. In Nord Kivu, the adjusted ANC coverage was $95.1 \%$ (95\% CI 92.8-97.5\%) in 2010 , and $98.2 \%$ (95\% CI 96.7-99.8\%) in 2018. In Sud Kivu, the adjusted ANC coverage was $89.5 \%$ (95\% CI $86.1-92.8 \%$ ) in 2010 and $90.0 \%$ (95\% CI $86.4-93.5 \%)$ in 2018, as shown in Table 2. The trends of adjusted ANC coverage were consistent between rural and urban regions in the DRC

Figure 2(B) shows the trend of adjusted skilled birth attendance coverage in the DRC from 2010 to 2018. In contrast to the adjusted ANC coverage, the adjusted skilled birth attendance coverage increased in most provinces. However, there was still a decrease in Kasai Oriental, with the adjusted skilled birth attendance coverage decreasing from $69.5 \%$ (95\% CI 64.3-74.7\%) in 2010 to $66.9 \%$ (95\% CI 62.8-71.0\%) in 2018 (Table 2).

\section{The prevalence of maternal health care service for women in different SES}

Figure 3 presents the adjusted ANC coverage and adjusted skilled birth attendance coverage for women from different wealth index groups in the Kasai region, the Kivu region, and the other provinces in the DRC. 
Table 1 Characteristics of the study participants by survey year

\begin{tabular}{|c|c|c|c|c|c|c|}
\hline \multirow[t]{2}{*}{ Variables } & \multicolumn{3}{|l|}{$\begin{array}{l}2010 \\
(\mathrm{~N}=4,807)\end{array}$} & \multicolumn{3}{|l|}{$\begin{array}{l}2018 \\
(\mathrm{~N}=8,554)\end{array}$} \\
\hline & Numbers & $\%$ (unweighted) $^{a}$ & $\%$ (weighted) $^{b}$ & Numbers & $\%$ (unweighted) $^{a}$ & $\%$ (weighted) $^{b}$ \\
\hline Antenatal care coverage & 4,159 & 86.5 & 87.3 & 6,554 & 76.6 & 82.4 \\
\hline Skilled birth attendance coverage & 3,686 & 76.7 & 74.2 & 6,361 & 74.4 & 85.2 \\
\hline \multicolumn{7}{|l|}{ Age } \\
\hline $15-19$ & 450 & 9.4 & 9.8 & 873 & 10.2 & 10.1 \\
\hline $20-29$ & 2,632 & 54.8 & 54.7 & 3,858 & 45.1 & 45.0 \\
\hline $30-39$ & 1,401 & 29.1 & 28.9 & 3,197 & 37.4 & 37.5 \\
\hline $40-49$ & 324 & 6.7 & 6.7 & 626 & 7.3 & 7.4 \\
\hline \multicolumn{7}{|l|}{ Educational attainment } \\
\hline Below primary & 1,066 & 22.2 & 23.4 & 1,872 & 21.9 & 17.6 \\
\hline Primary & 2,008 & 41.8 & 44.2 & 3,408 & 39.8 & 34.4 \\
\hline Secondary or higher & 1,733 & 36.1 & 32.4 & 3,274 & 38.3 & 47.8 \\
\hline \multicolumn{7}{|l|}{ Marital status } \\
\hline Currently Single & 622 & 13.1 & 13.3 & 1,108 & 13.0 & 15.1 \\
\hline Married or living with a partner & 4,137 & 86.9 & 86.7 & 7,446 & 87.0 & 84.9 \\
\hline \multicolumn{7}{|l|}{ Residential region } \\
\hline Rural & 3,100 & 64.9 & 74.6 & 6,287 & 73.5 & 61.6 \\
\hline Urban & 1,707 & 35.1 & 25.3 & 2,267 & 26.5 & 38.4 \\
\hline \multicolumn{7}{|l|}{ Wealth index group } \\
\hline Poorest & 951 & 19.5 & 22.3 & 2,873 & 33.6 & 24.3 \\
\hline Poorer & 962 & 20.0 & 21.9 & 2,270 & 26.5 & 21.6 \\
\hline Middle & 939 & 19.7 & 20.3 & 1,713 & 20.0 & 19.7 \\
\hline Wealthier & 1,069 & 22.2 & 19.7 & 1,160 & 13.6 & 19.4 \\
\hline Wealthiest & 886 & 18.4 & 15.8 & 538 & 6.3 & 14.9 \\
\hline \multicolumn{7}{|l|}{ Province } \\
\hline Bandundu & 417 & 8.7 & 11.0 & 840 & 9.8 & 12.0 \\
\hline Bas Congo & 346 & 7.2 & 6.0 & 263 & 3.1 & 6.2 \\
\hline Equateur & 477 & 9.9 & 12.1 & 1,665 & 19.5 & 6.5 \\
\hline Kasai Occidental & 453 & 9.4 & 6.3 & 759 & 8.9 & 8.7 \\
\hline Kasai Oriental & 462 & 9.6 & 8.2 & 1,129 & 13.2 & 8.6 \\
\hline Katanga & 552 & 11.5 & 18.3 & 1,422 & 16.6 & 17.0 \\
\hline Kinshasa & 372 & 7.7 & 9.1 & 255 & 3.0 & 10.2 \\
\hline Nord Kivu & 453 & 9.4 & 8.7 & 339 & 4.0 & 8.3 \\
\hline Sud Kivu & 484 & 10.1 & 8.2 & 389 & 4.5 & 8.9 \\
\hline Maniema & 424 & 8.8 & 2.9 & 324 & 3.8 & 1.4 \\
\hline Province Orientale & 367 & 7.6 & 9.2 & 1,169 & 13.7 & 12.2 \\
\hline \multicolumn{7}{|l|}{ Household head's sex } \\
\hline Male & 4,193 & 87.2 & 87.5 & 6,514 & 76.2 & 75.9 \\
\hline Female & 614 & 12.8 & 12.5 & 2,040 & 23.8 & 24.1 \\
\hline
\end{tabular}

Notes:

a Unweighted proportion is the fraction of the number of the group over the whole population in this study

${ }^{b}$ Weighted proportion was based on the unweighted proportion and further weighted by sampling weights provided in the MICS dataset

For adjusted ANC coverage, a general decreasing trend from 2010 to 2018 was observed in the Kasai region and other provinces in the DRC. The most significant decline of adjusted ANC coverage in the Kasai region was in the poorest women from $73.7 \%$ (95\% CI
$66.8-80.6 \%)$ in 2010 to $60.5 \%$ (95\% CI $53.3-67.7 \%)$ in 2018. In contrast to most provinces in the DRC, there was an increasing trend of adjusted ANC coverage for all groups in the Kivu region. Within each wealth index group in 2018, the adjusted ANC coverage in the Kivu 

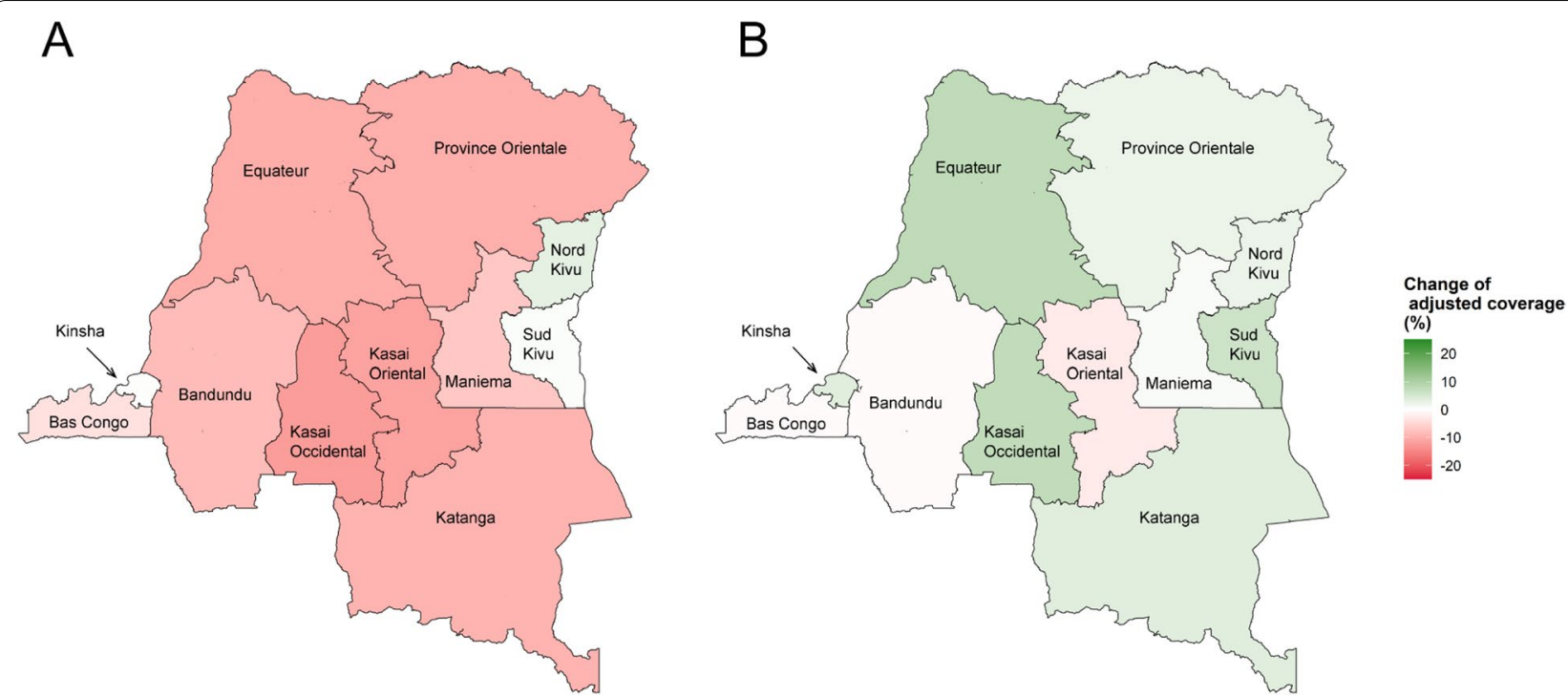

Fig. 2 The change of adjusted coverage of maternal health services in the DRC 2010 - 2018. Legends: a Panel A represents the change of adjusted coverage of antenatal care and Panel B represents the change of adjusted coverage of skilled birth attendance. $\mathbf{b}$ Positive figures in the legend which was shown as green on the map present the increase of adjusted coverage from 2010 to 2018. Negative figures (Red on the map) present the decrease of the adjusted coverage. c The adjusted coverage was calculated after adjusting for women's age, educational attainment, marital status, household heads'sex, residential region, and household wealth index groups

Table 2 Adjusted coverages of maternal health service in the DRC 2010 - $2018^{a}$

\begin{tabular}{|c|c|c|c|c|c|c|c|c|}
\hline \multirow[t]{3}{*}{ Province } & \multicolumn{4}{|l|}{ Antenatal Care } & \multicolumn{4}{|c|}{ Skilled Birth Attendance } \\
\hline & \multicolumn{2}{|l|}{$2010(N=4,807)$} & \multicolumn{2}{|l|}{$2018(\mathrm{~N}=8,554)$} & \multicolumn{2}{|l|}{$2010(N=4,807)$} & \multicolumn{2}{|l|}{$2018(\mathrm{~N}=8,554)$} \\
\hline & Percentage (\%) & $95 \% \mathrm{Cl}(\%)$ & Percentage (\%) & $95 \% \mathrm{Cl}(\%)$ & Percentage (\%) & $95 \% \mathrm{Cl}(\%)$ & Percentage (\%) & $95 \% \mathrm{Cl}(\%)$ \\
\hline Bandundu & 90.4 & $87.1-93.7$ & 82.0 & $78.5-85.5$ & 84.7 & $80.4-88.9$ & 84.0 & $80.8-87.3$ \\
\hline Bas Congo & 95.4 & $92.8-98.0$ & 91.6 & 87.8-95.4 & 94.5 & $91.3-97.7$ & 93.9 & $90.5-97.3$ \\
\hline Equateur & 84.3 & $80.3-88.2$ & 74.1 & $70.5-77.7$ & 50.9 & $45.6-56.2$ & 58.6 & $54.5-62.8$ \\
\hline Kasai Occidental & 81.0 & $76.7-85.4$ & 68.8 & $64.2-73.3$ & 69.5 & $64.4-74.7$ & 77.1 & $73.1-81.0$ \\
\hline Kasai Oriental & 79.4 & 74.9-84.0 & 67.9 & $63.7-72.2$ & 69.5 & $64.3-74.7$ & 66.9 & $62.8-71.0$ \\
\hline Katanga & 80.1 & $75.6-84.5$ & 70.7 & $66.7-74.8$ & 63.0 & $57.9-68.2$ & 66.7 & $62.7-70.6$ \\
\hline Kinshasa & 94.6 & $92.1-97.1$ & 94.9 & $92.0-97.8$ & 96.0 & 93.4-98.6 & 99.6 & $98.6-100.0$ \\
\hline Maniema & 76.7 & 71.7-81.6 & 69.8 & 63.9-75.6 & 70.5 & $65.2-75.8$ & 71.3 & $65.6-77.0$ \\
\hline Nord Kivu & 95.1 & $92.8-97.5$ & 98.2 & $96.7-99.8$ & 95.4 & $93.0-97.7$ & 97.6 & $95.8-99.5$ \\
\hline Province Orientale & 90.7 & $87.1-94.4$ & 80.8 & $77.3-84.2$ & 82.6 & $77.6-87.5$ & 84.9 & $82.0-87.9$ \\
\hline Sud Kivu & 89.5 & $86.1-92.8$ & 90.0 & $86.4-93.5$ & 80.2 & $75.6-84.7$ & 86.1 & 81.9-90.3 \\
\hline
\end{tabular}

Notes:

a Adjusted prevalence was calculated after adjusting for women's age, educational attainment, marital status, household heads' sex, residential region, and household wealth index group

region was higher than in the other provinces. When it comes to the adjusted skilled birth attendance coverage, there was a general increasing trend in the DRC. The largest increment was observed women in the Kivu region from $71.2 \%$ (95\% CI 58.2-84.2\%) in 2010 to
$89.1 \%$ (95\% CI 81.5-96.8\%) in 2018. Besides, except for the wealthiest women, the adjusted skilled birth attendance coverage in the Kivu region was higher than in the other provinces for all wealth index groups in 2018. 


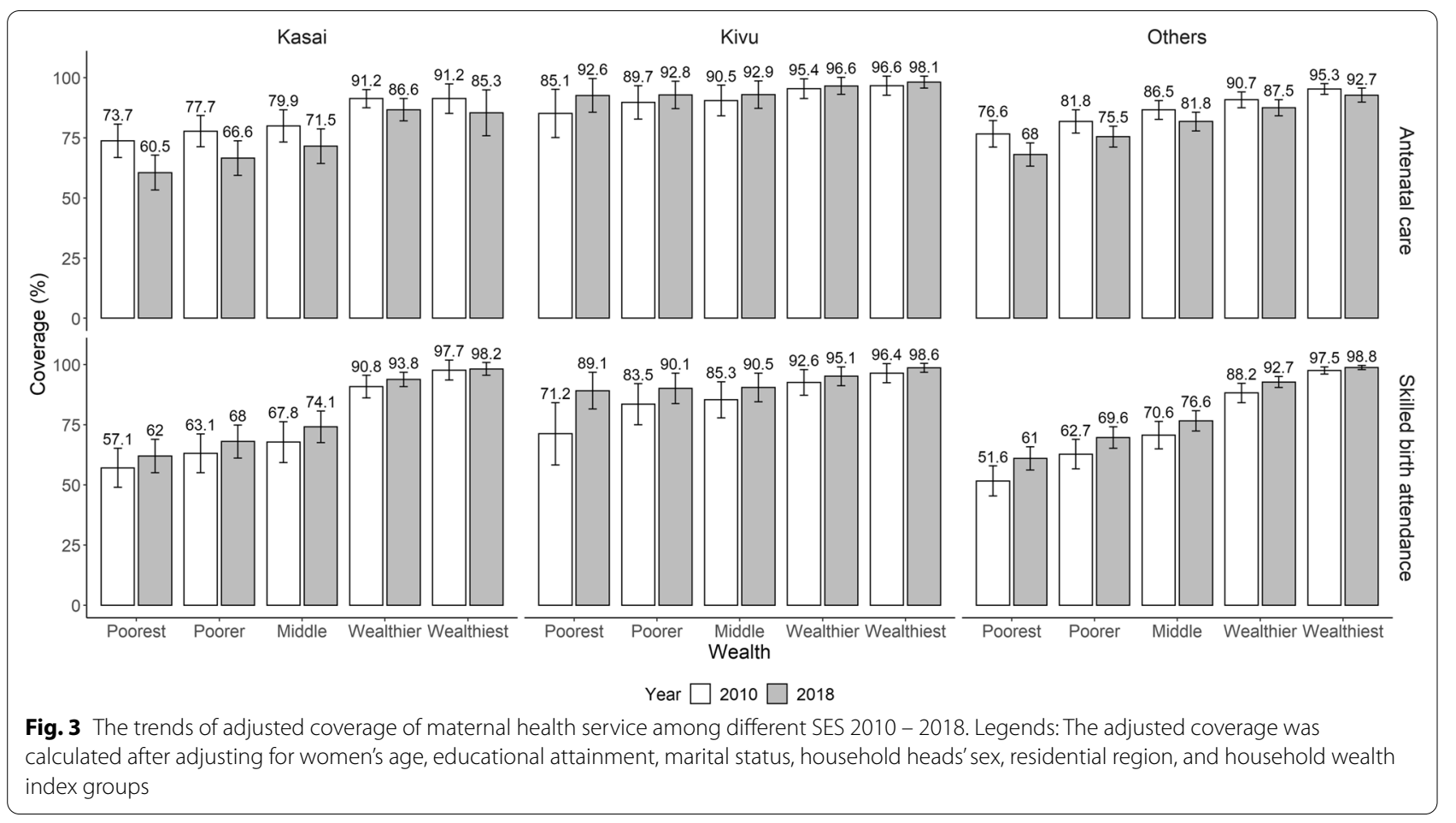

\section{Discussion}

In the present study, we observed a decline of ANC coverage in the DRC from 2010 to 2018, while we observed an increase in skilled birth attendance during the same time period. Both ANC coverage and skilled birth attendance coverage were found to have declined in Kasai Oriental, while both were found to have increased in the Kivu region. The largest decline in ANC was observed among women in the Kasai region. However, for women in the Kivu region, those in the lowest SES group saw a significant increase in both ANC coverage and skilled birth attendance coverage.

The DRC, with the most severe health challenge of its high maternal mortality ratio, has received a large amount of health assistance from various international organizations, of which a significant share was devoted to maternal and reproductive health interventions [3638]. However, given the political instability and armed conflict, not all health assistance programs were effective. The results of this study suggested that skilled birth attendance coverage has increased from 2010 to 2018, which was consistent with the overall trend in Western and Central Africa [10]. This increase illustrated great progress made by the programs targeting improving the delivery situation $[39,40]$. However, the ANC coverage was found to decrease in most regions, with the countrylevel coverage below the world average[9]. The conflicts in the country and the lack of funding for the maternal health service from the DRC government contributed to the decline. ANC plays a crucial role in promoting maternal health [41-43]. The low level of ANC coverage suggests that more efforts and targeted public health interventions are needed to promote maternal and child health in the DRC.

It was found that the ANC coverage and skilled birth attendance coverage both decreased in Kasai Oriental, indicating a systemic problem in the province. Due to the horrific violence that erupted in 2016, women in the Kasai region were reported to have limited access to essential health care [23]. Previous studies found that serious atrocities in the Kasai region forced people to leave their homes and even their country [44]. While some of them are returning, the situation in the Kasai remains volatile as the wider political situation continues to deteriorate. Maternal health service coverage there was inadequate. Unlike the Kasai region, where health intervention programs have not been fully implemented yet, the Kivu region has received continuous international health assistance for sexual and reproductive health. A previous study showed that the operational capacity score for primary emergency obstetric care in Nord Kivu and Sud Kivu ranked second and third in the whole country, respectively, making them just behind Kinshasa, the capital province of the DRC [45]. The Kivu region also had the highest percentage of health facilities with family planning services available [38]. Furthermore, 
the Kivu region consists of bigger cities with higher population density compared to other provinces, potentially providing residents with greater access to healthcare facilities [46]. Consistent with previous findings, the present study found that the coverage of ANC and skilled birth attendance increased from 2010 to 2018 in the Kivu region, given the circumstance of an overall decline of ANC coverage at the country level. Despite the long-lasting instabilities, which may have caused difficulties for women to have access to adequate maternal health care in the region, such results demonstrated the potential efficiency of health aid in the Kivu region.

Additionally, health interventions and social changes usually have differentiated impacts concerning health service coverage based on people's SES [47]. It was reported that the domestic conflict in the Kasai region had affected 170 health centers as of October 2017, leaving women with limited access to health care [24]. Without adequate local health care services, many women have to travel to distant health centers to seek maternal health services. Hence, traveling costs have become an obstacle for low-income families. On the other hand, although influenced by longer conflicts durations, the situation of women with low SES in the Kivu region has improved over the years. The coverage of skilled birth attendance in women with the lowest SES was found to increase by one quarter, more extensive than most of their wealthier peers. Although disparities in maternal health care coverage among different SES groups still exist, it is gradually being reduced in the Kivu region. The differing trends between the Kasai and Kivu regions demonstrate the critical role of international health aid. Health centers with better access to international health aid may be able to provide health services with better accessibility and affordability to vulnerable populations such as mothers and children.

The results of this study also indicate that ANC and skilled birth attendance coverage in the Kivu region was higher compared to other provinces with little or no conflicts. Although it demonstrates the effectiveness of the health interventions, another question arises -- whether further health resources should be reallocated to other regions of the country? On the one hand, Kivu is still in conflict and is facing the consequential impacts of an Ebola outbreak from February to May 2021 [48]. Continued health aid is needed to keep the high level of maternal health service coverage in the area. On the other hand, maternal health coverage in other provinces in the DRC was much lower than that in the Kivu region. Accessible and affordable health service was also in urgent need for those regions. The vertical health aid programs targeting specific conflict areas may largely ignore the poor situation in other parts of the country, and a horizontal investment of the country's overall health system should be considered as a priority.

\section{Strength and limitations}

To our knowledge, this article is one of the first studies exploring the temporal trends of maternal health service coverage in the DRC by using two rounds of nationally representative surveys of the MICS4 and MICS6. We applied adjusted prevalence to provide an unbiased estimate of the health service coverage in DRC by region and individual's socioeconomic status. Besides, our results illustrate how conflicts impact women of different SES in the Kasai and Kivu regions and the potential role of international health aid in conflicting areas.

There are several limitations to this study. Firstly, without comparable indicators in MICS1 and MICS2 in the DRC, long-term trends of maternal health service coverage could not be entirely assessed in this study. Secondly, due to the re-division of the provinces in 2015, the sampling processes were slightly different between MICS4 and MICS6 at the province level. To make it comparable between the two surveys, we re-categorized the provinces in MICS6 into those in MICS4. The low spatial resolution caused by combining current provinces together makes our findings less precise in large provinces such as Equateur province which was divided into 4 smaller provinces in 2015. Thirdly, other confounders such as the supply of skilled birth attendants, the number of health facilities in each province, and health expenditure are not fully measured in the MICS survey, and not included in this study. Lastly, the method of adjusted prevalence has its limitations. Although it can compare groups efficiently and achieve the goals of unbiased estimation of population prevalence, it is substantially more challenging to attain when the sampling strategy is more complicated than the simple random sampling schemes. Also, the variation of estimates for groups with small sizes is relatively large.

\section{Conclusions}

Based on the analysis of two rounds of MICS data in the DRC, opposite trends in the coverages of ANC and skilled birth attendance were found between 2010 and 2018. Overall, while the skilled birth attendance coverage increased, the ANC coverage decreased over the years. In Kasai-Oriental, where conflicts newly erupted, the situation became worse for both services. Women with lower SES were found to have significantly less access to maternal health services. Although influenced by longlasting conflicts, the Kivu region saw an increase both in ANC coverage and skilled birth attendance coverage. The disparities between women in higher and lower SES have also slightly reduced from 2010 to 2018 in the Kivu region. There was a higher maternal health service 
coverage in the Kivu region despite conflicts, suggesting a successful implementation of an international health aid program. However, this raised further questions of the effective resource allocation and the role of international health aid in supporting vertical programs versus horizontal programs.

\section{Abbreviations}

DRC: the Democratic Republic of the Congo; ANC: antenatal care; UNICEF: United Nations Children's Fund; MICS: Multiple Indicators Cluster Survey; SES: socioeconomic status.

\section{Supplementary Information}

The online version contains supplementary material available at https://doi. org/10.1186/s12884-021-04220-7.

Additional file 1. Approximate corresponding boundaries of provinces between MICS 2010 and MICS 2017-2018. On 9 January 2015, the National Assembly of the DRC passed a law on the new administrative divisions of the country. To make the province variables in MICS6 (2017-2018) comparable with the data in MICS4 (2010), we re-categorized the provinces in MICS6 into the division system in 2010. Table 1 presents the correspondence of provinces between 2010 and 2018.

Additional file 2. Weighted coverage in the country-level and adjusted coverage in the province-level of receiving at least four times antenatal care in the DRC in 2010 and 2018.

Additional file 3. Sensitivity analysis of the adjusted coverage in the other provinces. Each province excpet those in the Kasai reigon and the Kivu region was dropped out in turns to check if any specific province impacted the adjusted coverage of the maternal health service in the other provinces significantly. These provinces includes: Kinshasa, Base Congo, Bandundu, Equateur, Orientale, Maniema, and Katanga.

Additional file 4. Adjusted coverage of maternal health service in urban and rural regions of DRC from 2010 to 2018. Detailed adjusted coverage of maternal health services in urban and rural regions of the DRC from 2010 to 2018.

\section{Acknowledgements}

We thank Jia Yi Hee for assisting the revision of the article.

\section{Authors' contributions}

F.G. contributed to the study concept and design, statistical analysis, results interpretation and was a major contributor in writing the manuscript. X.Q. and $H . X$. contributed to the study concept and design, and drafting and revision of the manuscript. Q.H., T.Z., S.Z., H.W., R.T., and K.T. contributed to study concept and design and revision of the manuscript. All authors reviewed and approved the final manuscript.

\section{Funding}

This work is supported by National Natural Science Foundation of China (No. 72074130) and the Breeze Foundation of Tsinghua University (No. 20203080035). The research funds were mainly used. for the design, data analysis and for the publication of the paper.

\section{Availability of data and materials}

The datasets generated and/or analyzed during the current study are available in the UNICEF MICS survey home page, [https://mics.unicef.org/surveys/].

\section{Declarations}

Ethics approval and consent to participate

The data used in the study consisted of publicly available de-identified datasets, which was retrieved from the UNICEF MICS website with permission.
Further information on the ethics approval and participants' consent can be found in the published MICS reports. All methods were carried out in accordance with the ethical standards in the 1964 Declaration of Helsinki and its later amendments or comparable ethical standards.

\section{Consent for publication}

Not applicable.

\section{Competing interests}

The authors declare that they have no competing interests.

\section{Author details}

${ }^{1}$ Vanke School of Public Health, Tsinghua University, No. 30 Shuangqing Road, 100084 Beijing, China. ${ }^{2}$ Health Section Programme Division, UNICEF Headquarters, 3 United Nations Plaza, New York, NY 10017, USA.

Received: 1 January 2021 Accepted: 21 October 2021

Published online: 05 November 2021

\section{References}

1. World Health Organization. Maternal Health. 2019. https://www.who.int/ health-topics/maternal-health\#tab=tab_1. Accessed 6 Sep 2020.

2. Onasoga OA, Afolayan JA, Oladimeij BD. Factor's influencing utilization of antenatal care services among pregnant women in Ife Central LGA, Osun State Nigeria. Advances in Applied Science Research. 2012;3:1309-15.

3. Graham WJ, Bell JS, Bullough CHW. Can skilled attendance at delivery reduce maternal mortality in developing countries? Safe motherhood strategies: a review of the evidence. 2001.

4. Bell J, Hussein J, Jentsch B, Scotland G, Bullough C, Graham W. Improving skilled attendance at delivery: a preliminary report of the SAFE strategy development tool. Birth. 2003;30:227-34.

5. Karkee R, Lee AH, Khanal V. Need factors for utilisation of institutional delivery services in Nepal: an analysis from Nepal Demographic and Health Survey, 2011. BMJ open. 2014;4.

6. World Health Organization. Trends in maternal mortality: 1990 to 2008. 2010. https://www.who.int/reproductivehealth/publications/monitoring/ 9789241500265/en/. Accessed 3 Oct 2021.

7. Maternal mortality ratio (modeled estimate, per 100,000 live births) Congo, Dem. Rep. | Data. https://data.worldbank.org/indicator/SH.STA. MMRT?locations=CD. Accessed 8 Oct 2021

8. United Nations. SDG Indicators — SDG Indicators. https://unstats.un.org/ sdgs/metadata?Text=\&Goal=3\&Target=3.1. Accessed $21 \mathrm{Jul} 2021$.

9. United Nations Children's Fund. Antenatal care. 2019. https://data.unicef. org/topic/maternal-health/antenatal-care/\#more--1590. Accessed 4 Oct 2020

10. United Nations Children's Fund. Delivery care. 2020. https://data.unicef. org/topic/maternal-health/delivery-care/. Accessed 22 Jul 2021.

11. Plan I national de la statistique du M du. MICS-Palu 2018 Situation and living conditions of children, women and men in the Democratic Republic of Congo. 2019.

12. Soeters R, Peerenboom PB, Mushagalusa P, Kimanuka C. Performancebased financing experiment improved health care in the Democratic Republic of Congo. Health Affairs. 2011;30:1518-27.

13. Woolcock M. Engaging with fragile and conflict-affected states: An alternative approach to theory, measurement and practice. WIDER Working Paper; 2014.

14. Democratic Republic of the Congo, Conflict in the Kivus | How does law protect in war? - Online casebook. https://casebook.icrc.org/case-study/ democratic-republic-congo-conflict-kivus. Accessed 7 Oct 2021.

15. International committee of the red cross. Democratic Republic of the Congo: The only thing left in Kasai was the land I ICRC. https://www.icrc. org/en/document/democratic-republic-congo-only-thing-left-kasai-wasland. Accessed 22 Jul 2021.

16. Congo's Kasaï Provinces Conflict Assessment - Democratic Republic of the Congo | ReliefWeb. https://reliefweb.int/report/democratic-repub lic-congo/congo-s-kasa-provinces-conflict-assessment. Accessed 8 Oct 2021. 
17. DR Congo: Fostering peace and reconciliation in Kasaï and Kasaï-Central - Interpeace: Interpeace. https://www.interpeace.org/2020/08/fosteringpeace-and-reconciliation-drc/. Accessed 8 Oct 2021.

18. Cross I committee of the red. Nutrition and survival in Kasai | ICRC. https://www.icrc.org/en/document/drc-conflict-food-children-farmingnutrition-survival-kasai. Accessed 22 Jul 2021.

19. World Health Organization. WHO strategic response and operations plan 2018, the Democratic Republic of the Congo. 2018.

20. UNFPA East and Southern Africa. Women attend life-saving mobile clinics in conflict-torn Kasai, DR Congo. 2017.

21. World Health Organization; United Nations Children's Fund. UNICEF for every child. What we do. 2020. https://www.unicef.org/drcongo/en. Accessed 8 Oct 2021.

22. Alberti KP, Grellety E, Lin Y-C, Polonsky J, Coppens K, Encinas L, et al. Violence against civilians and access to health care in North Kivu, Democratic Republic of Congo: three cross-sectional surveys. Conflict and Health. 2010;4:17.

23. World Health Organization; United Nations Children's Fund. Conflict in the Kasai, Democratic Republic of the Congo. 2017. https://www.unicef. org/child-alert/democratic-republic-of-congo. Accessed 8 Oct 2021.

24. UNFPA East and Southern Africa. Women attend life-saving mobile clinics in conflict-torn Kasai, DR Congo. 2017. https://esaro.unfpa.org/en/news/ women-attend-life-saving-mobile-clinics-conflict-torn-kasai-dr-congo. Accessed 8 Oct 2021

25. DRC - Emergency Response to Kasai Conflict - COD181 (Full Appeal) Democratic Republic of the Congo| ReliefWeb. https://reliefweb.int/ report/democratic-republic-congo/drc-emergency-response-kasai-confl ict-cod181-full-appeal. Accessed 19 Jul 2021.

26. Ministry of Planning and Monitoring the Implementation of the Revolution of the Revolution of Modernity. Multiple Indicator Cluster Survey MICS-2010: Monitoring the situation of children and women Summary Report. 2011. https://www.unicef.org/drcongo/en/reports/multiple-indic ator-cluster-survey-2010. Accessed 9 May 2020.

27. Howe LD, Galobardes B, Matijasevich A, Gordon D, Johnston D, Onwujekwe $\mathrm{O}$, et al. Measuring socio-economic position for epidemiological studies in low- and middle-income countries: a methods of measurement in epidemiology paper. Int J Epidemiol. 2012:41:871-86.

28. World Health Organization. The Global Health Observatory. 2020. https:// www.who.int/data/gho/data/indicators. Accessed 8 Oct 2021.

29. Abosse Z, Woldie M, Ololo S. Factors influencing antenatal care service utilization in hadiya zone. Ethiopian J Health Sci. 2010;20.

30. Jayaraman A, Chandrasekhar S, Gebreselassie T. Factors affecting maternal health care seeking behavior in Rwanda. DHS Working Papers No. 59 2008.

31. Woldemicael G, Tenkorang EY. Women's autonomy and maternal healthseeking behavior in Ethiopia. Maternal Child Health J. 2010;14:988-98.

32. Navaneetham K, Dharmalingam A. Utilization of maternal health care services in Southern India. Social Sci Med. 2002;55:1849-69.

33. Ye Y, Yoshida Y, Harun-Or-Rashid MD, Sakamoto J, Sakamoto J. Factors affecting the utilization of antenatal care services among women in Kham District, Xiengkhouang province, Lao PDR. Nagoya J Med Sci. 2010;72:23-33.

34. Santos CAST, Fiaccone RL, Oliveira NF, Cunha S, Barreto ML, do Carmo $M B B$, et al. Estimating adjusted prevalence ratio in clustered cross-sectional epidemiological data. BMC Med Res Methodol. 2008;8:80.
35. Beckett LA, Scherr PA, Evans DA. Population prevalence estimates from complex samples. J Clin Epidemiol. 1992:45:393-402.

36. Altare C, Malembaka EB, Tosha M, Hook C, Ba H, Bikoro SM, et al. Health services for women, children and adolescents in conflict affected settings: experience from North and South Kivu, Democratic Republic of Congo. Conflict and health. 2020;14:1-19.

37. Dumbaugh M, Bapolisi W, van de Weerd J, Zabiti M, Mommers P, Balaluka $G B$, et al. Evaluating the comparative effectiveness of different demand side interventions to increase maternal health service utilization and practice of birth spacing in South Kivu, Democratic Republic of Congo: an innovative, mixed methods approach. BMC Pregnancy Childbirth. 2017;17:212.

38. Mpunga D, Lumbayi JP, Dikamba N, Mwembo A, Ali Mapatano M, Wembodinga G. Availability and Quality of Family Planning Services in the Democratic Republic of the Congo: High Potential for Improvement. Global Health Science Practice. 2017:5:274-85.

39. Feinstein L, Dimomfu BL, Mupenda B, Duvall S, Chalachala JL, Edmonds A, et al. Antenatal and delivery services in Kinshasa, Democratic Republic of Congo: care-seeking and experiences reported by women in a household-based survey. Tropical medicine \& international health: TM \& IH. 2013;18:1211-21.

40. Lee H, Park SJ, Ndombi GO, Nam EW. Community-based maternal and child health project on 4+ antenatal care in the Democratic Republic of Congo: a difference-in-differences analysis. Reproductive Health. 2019:16:1-10.

41. Pradhan A. Situation of antenatal care and delivery practices. Kathmandu Univ Med J. 2005;3:266-70.

42. Iyaniwura CA, Yussuf Q. Utilization of antenatal care and delivery services in Sagamu, south western Nigeria. African journal of reproductive health. 2009;13.

43. Wilunda C, Quaglio G, Putoto G, Takahashi R, Calia F, Abebe D, et al. Determinants of utilisation of antenatal care and skilled birth attendant at delivery in South West Shoa Zone, Ethiopia: a cross sectional study. Reproductive Health. 2015;12:1-12.

44. The Internatioanl Refugee Rights Initiative. Conflict and Displacement in the Kasai. 2018.

45. Mpunga Mukendi D, Chenge F, Mapatano MA, Criel B, Wembodinga G. Distribution and quality of emergency obstetric care service delivery in the Democratic Republic of the Congo: it is time to improve regulatory mechanisms. Reproductive Health. 2019;16:102.

46. Provinces of the Democratic Republic of the Congo | Mappr. https:// www.mappr.co/counties/congo-provinces/. Accessed 8 Oct 2021.

47. Deaton A. Health, inequality, and economic development. J Econ Literature. 2003;41:113-58.

48. Ebola outbreak 2021- North Kivu. https://www.who.int/emergencies/ situations/ebola-2021-north-kivu. Accessed 8 Oct 2021.

\section{Publisher's Note}

Springer Nature remains neutral with regard to jurisdictional claims in published maps and institutional affiliations.

Ready to submit your research? Choose BMC and benefit from

- fast, convenient online submission

- thorough peer review by experienced researchers in your field

- rapid publication on acceptance

- support for research data, including large and complex data types

- gold Open Access which fosters wider collaboration and increased citations

- maximum visibility for your research: over 100M website views per year

At $\mathrm{BMC}$, research is always in progress.

Learn more biomedcentral.com/submissions 